\title{
Landsat 8
}

The Landsat Data Continuity Mission (named Landsat 8 after on-orbit initialization and verification) launched from Vandenberg Air Force Base in California on February 11, 2013, atop an Atlas V rocket. As with previous partnerships, this collaboration between the U.S. Geological Survey (USGS)

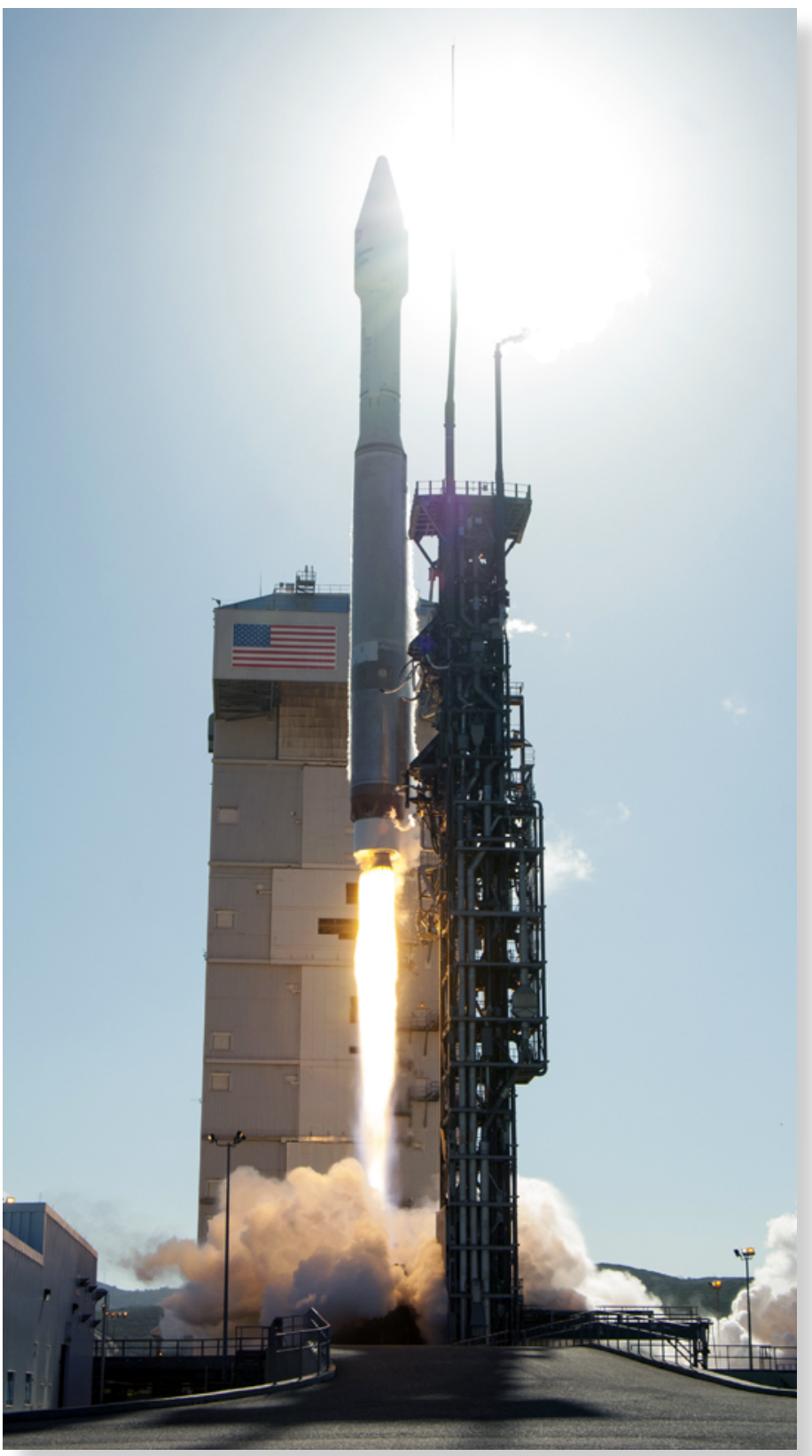

The Landsat Data Continuity Mission (LDCM) launch, February 11, 2013. and National Aeronautics and Space Administration (NASA) continues the mission to acquire high-quality data that meet both USGS and NASA scientific and operational requirements for observing land use and land cover change.

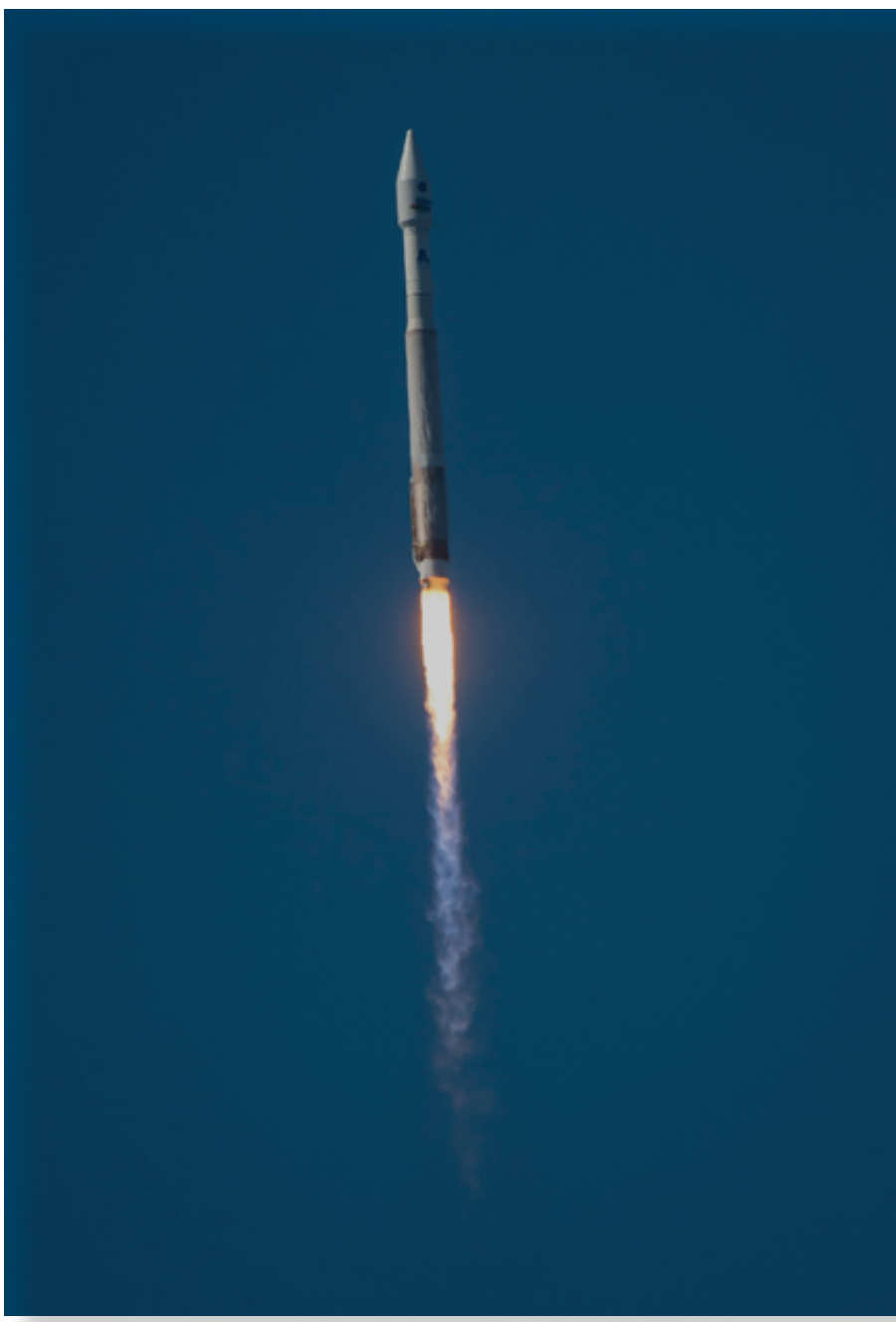

LDCM airborne during launch, February 11, 2013.

The Landsat era that began in 1972, providing global, synoptic, and repetitive coverage of the Earth's land surfaces, continues at a scale where natural and human-induced changes can be detected, differentiated, characterized, and monitored over time. 


\section{Landsat 8 Spacecraft and Instruments}

The Landsat 8 spacecraft, built by Orbital Sciences Corporation, has a 5-year mission design life, yet includes enough fuel for 10 years of operation. The centerpiece of the observatory is the Operational Land Imager (OLI), which was designed and built by the Ball Aerospace and Technologies Corporation. By collecting land-surface data with spatial resolution and spectral band specifications consistent with historical Landsat data, the OLI instrument advances future measurement capabilities while ensuring compatibility with historical data.

Designed as a push-broom sensor with a fourmirror telescope, higher signal-to-noise performance, and 12-bit quantization, the OLI collects data in the visible, near infrared, and shortwave infrared wavelength regions as well as a panchromatic band. Two new spectral bands have been added: a deep-blue band for coastal water and aerosol studies (band 1), and a band for cirrus cloud detection (band 9) (fig. 1). A Quality Assurance band is also included to indicate the presence of terrain shadowing, data artifacts, and clouds.

The Thermal Infrared Sensor (TIRS), built by NASA Goddard Space Flight Center, was added to the payload to continue thermal imaging and to support emerging applications such as modeling evapotranspiration for monitoring water use consumption over irrigated lands. The TIRS collects data in two long wavelength thermal infrared bands and has a 3 -year design life. The 100-meter spatial resolution of TIRS data is registered to the OLI data to create radiometrically and geometrically calibrated, terrain-corrected 16-bit Level 1 data products.

\section{LDCM to Landsat 8 Transition}

NASA managed the satellite during the on-orbit initialization and verification period after launch. Once the post launch assessment review and the mission transition reviews were completed, the USGS became responsible for the operations of the mission, including: health and safety of the spacecraft; orbital maintenance; and collecting, archiving, processing, and distributing data products.

The data received from Landsat 8 are processed using parameters consistent with all standard Landsat data products (table 1) and are available for download at no charge and with no user restrictions from EarthExplorer http://earthexplorer.usgs.gov, GloVis http://glovis.usgs.gov, or the LandsatLook Viewer at http://landsatlook.usgs.gov.

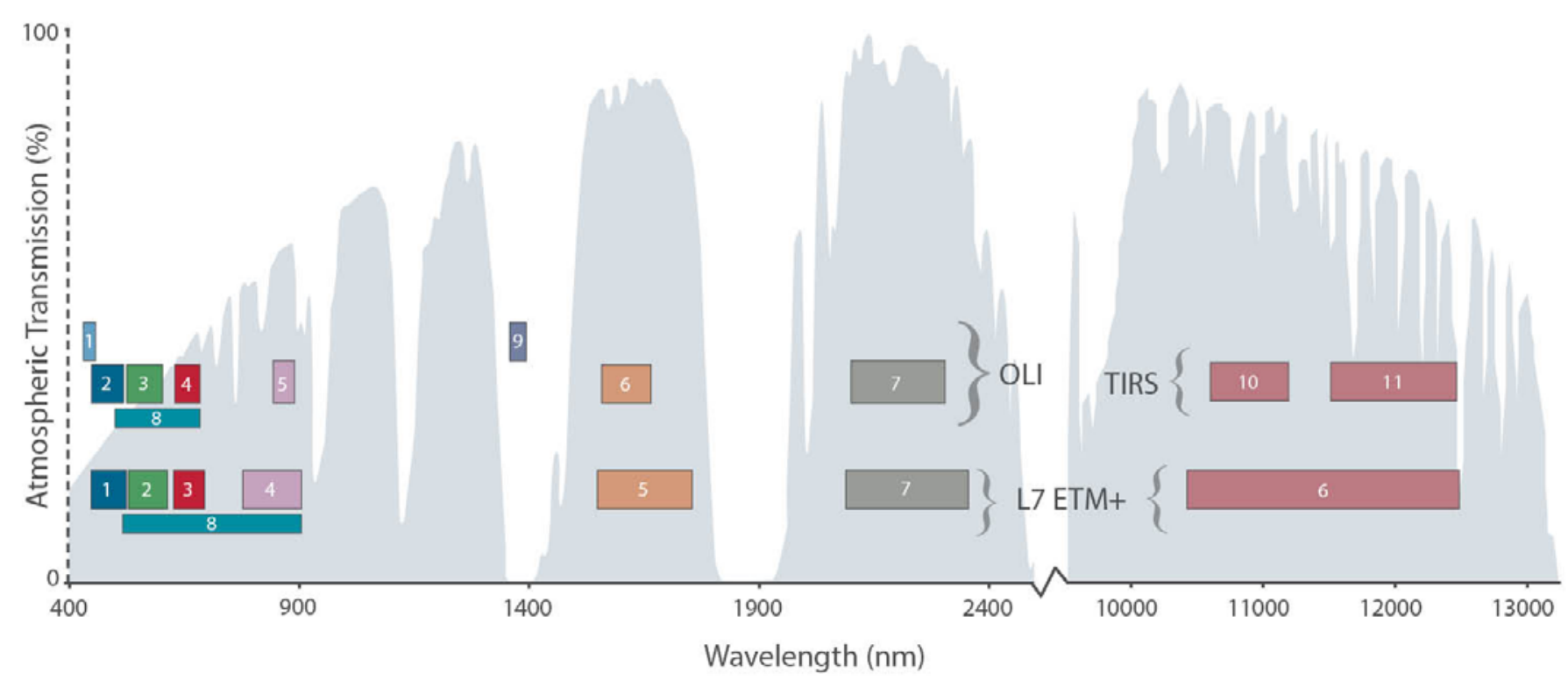

Figure 1. Band passes of the Landsat 8 Operational Land Imager (OLI) and Thermal Infrared Sensor (TIRS) instruments. 
Table 1. Processing parameters for Landsat 8 standard data products.

[UTM, Universal Transverse Mecator; WGS, World Geodetic System; OLI, Operational Land Imager; TIRS, Thermal Infrared Sensor]

\begin{tabular}{|c|c|}
\hline Product Type & Level 1T (terrain corrected) \\
\hline Data type & 16-bit unsigned integer \\
\hline Output format & GeoTIFF \\
\hline Pixel size & 15 meters $/ 30$ meters $/ 100$ meters (panchromatic/multispectral/thermal) \\
\hline Map projection & UTM (Polar Stereographic for Antarctica) \\
\hline Datum & WGS 84 \\
\hline Orientation & North-up (map) \\
\hline Resampling & Cubic convolution \\
\hline Accuracy & $\begin{array}{l}\text { OLI: } 12 \text { meters circular error, } 90 \text { percent confidence } \\
\text { TIRS: } 41 \text { meters circular error, } 90 \text { percent confidence }\end{array}$ \\
\hline
\end{tabular}

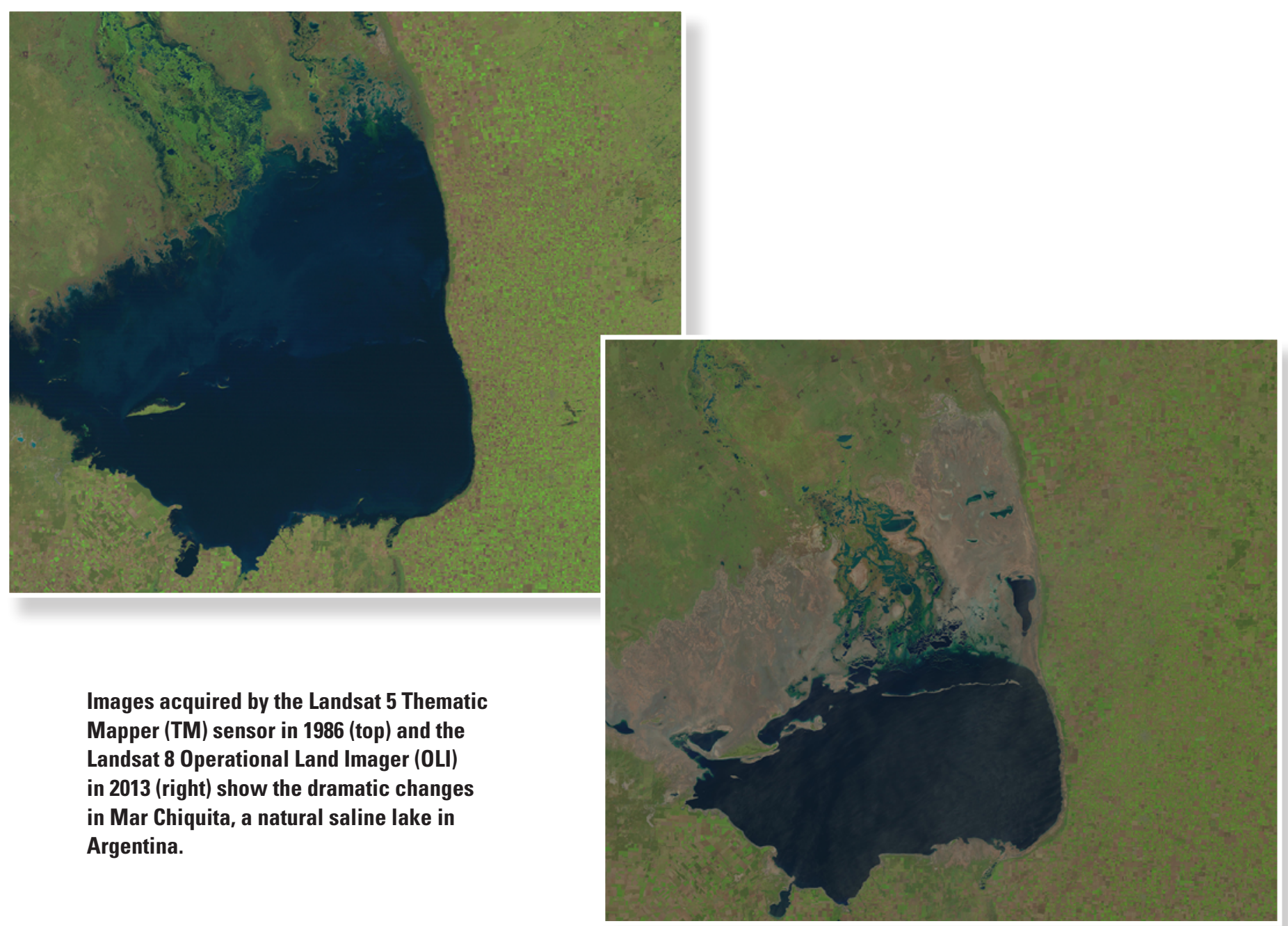




\section{Landsat Science Team}

The Landsat Science Team provides technical and scientific input to USGS and NASA to help ensure the success of the Landsat program while providing science support on issues including data acquisition, product access and format, and science and applications opportunities. Funded by the USGS and co-chaired by the USGS and NASA, members serve for 5 years and include scientists from industry, academia, and government.

The first team was established in 2005 and recommended strategies for the effective use of archived data from Landsat sensors and investigated the requirements for future sensors to meet the needs of Landsat users, including the needs of policy makers at all levels of government.

A second team was selected in 2012. They serve to address issues of importance to all Landsat users and play a key role in evaluating the new Landsat 8 data and ensuring that the Landsat 8 mission is successfully integrated with past, present, and future missions for observing national and global environmental systems.

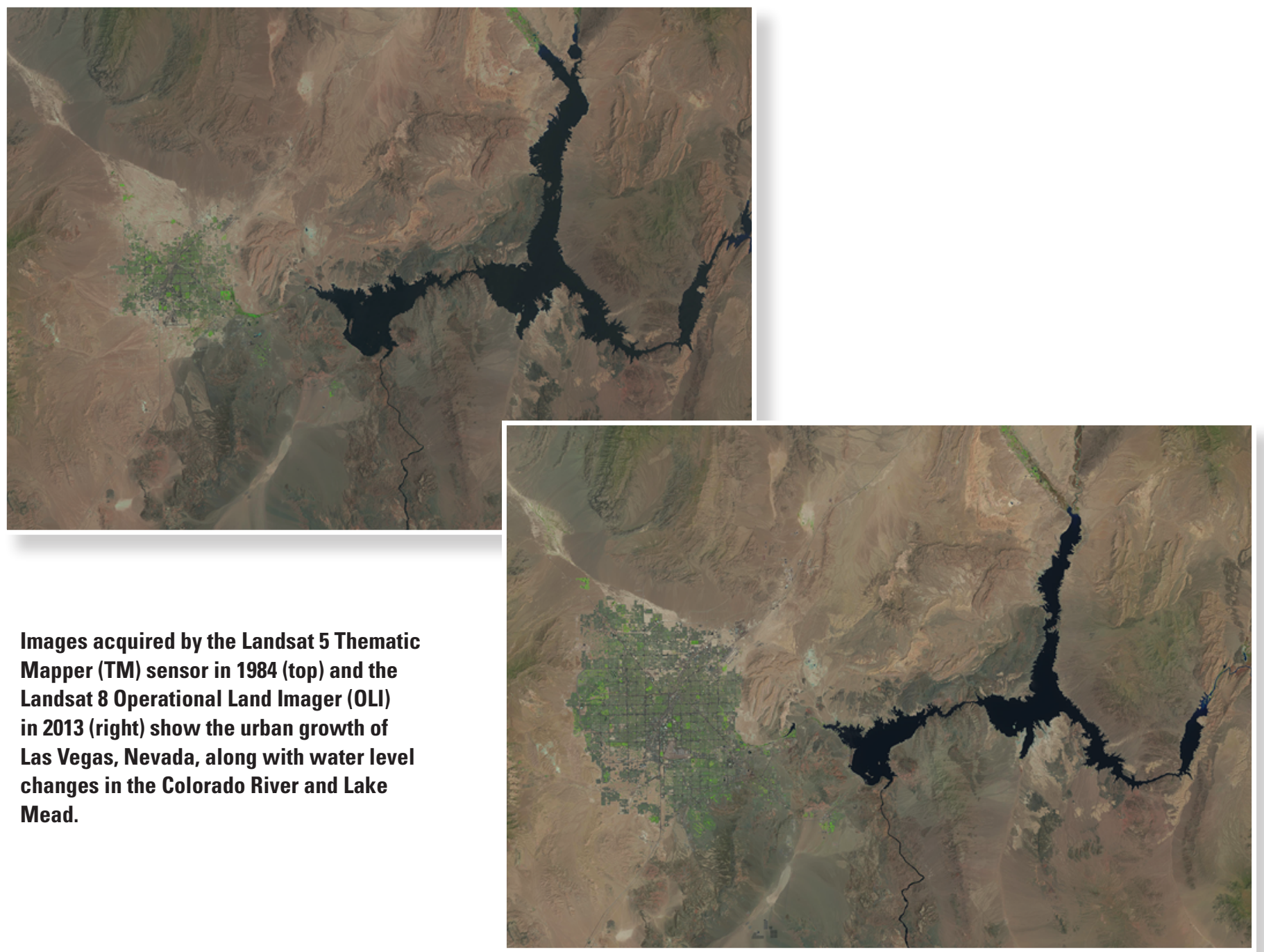

For information about Landsat operations, product specifications, or to receive updates and newsletters, visit

http://landsat.usgs.gov, http://ldcm.nasa.gov, or contact:

\section{USGS EROS}

Landsat Customer Service

Mundt Federal Building

Sioux Falls, SD 57198

Telephone: 605-594-6151 Fax: 605-594-6589

Email: custserv@usgs.gov
For information about the USGS Land Remote Sensing Program, visit

http://remotesensing.usgs.gov.

For additional information about the USGS, visit http://www.usgs.gov or http://ask.usgs.gov.

Any use of trade, firm, or product names is for descriptive purposes only and does not imply endorsement by the U.S. Government. 